J. Clin. Chem. Clin. Biochem.

Vol. 17, 1979, pp. 599-604

\title{
Zuverlässigkeit von Aminosäure-Bestimmungen aus menschlichem Serum bei unterschiedlichen Lagerungsbedingungen
}

.Von K. Olek, S. Uhlhaas, P. Wardenbach und M. Yamaguchi

Institut für Humangenetik der Universität Bonn

(Eingegangen am 4. April 1978/17. April 1979)

Zusammenfassung: Vollblut, Serum und enteiweißtes Serum werden bis zu $24 \mathrm{~h}$ bei Raumtemperatur und bis zu 30 Tagen bei $-30^{\circ} \mathrm{C}$ aufbewahrt. Dann werden auf einem automatischen Aminosäurenanalysator quantitativ die Aminosäuren bestimmt.

Selbst bei 24-stündigem Lagern von Vollblut bei Raumtemperatur ergeben sich bei den Aminosäuren Citrullin, $\alpha$ Aminobuttersäure, Cystein und Tryptophan keine Konzentrationsänderungen, während alle übrigen erhebliche $\mathrm{Zu}$ bzw. Abnahme zeigen. Im Serum ändern sich innerhalb von $24 \mathrm{~h}$ bei Raumtemperatur noch die Konzentrationen von Asparagin- und Glutaminsäure, Serin, Glycin, Cystein und Phenylalanin. Ausgenommen für die Bestimmung von Asparagin- und Glutaminsäure kann enteiweißtes Serum ohne Veränderung bis zu $24 \mathrm{~h}$ bei Raumtemperatur und bis zu einem Monat bei $-30^{\circ} \mathrm{C}$ aufbewahrt werden.

\section{Influence of storing conditions on the amino acid concentration in human serum}

Summary: Whole blood, serum and deproteinized serum were stored at room temperature up to $24 \mathrm{~h}$ and at $-30^{\circ} \mathrm{C}$ up to one month. The amino acid content was then determined with an automatic amino acid analyser.

When whole blood is left at room temperature the concentration of citrulline, $\alpha$-aminobutyric acid, cysteine and tryptophan remains unchanged, whereas the other amino acids show a remarkable increase or decrease.

In serum stored for $24 \mathrm{~h}$ at room temperature, only the concentrations of aspartic and glutamic acid, serine, cysteine and phenylalanine.were altered. With the exception of aspartic and glutamic acid it was possible to leave deproteinized serum up to $24 \mathrm{~h}$ at room temperature and up to one month at $-30^{\circ} \mathrm{C}$ without observing a change in the concentration of the other amino acids.

No change occurred, when serum was stored at $=30^{\circ} \mathrm{C}$ for $24 \mathrm{~h}$.

\section{Einleitung}

Verschiedene klinische Probleme erfordern die quantitative Bestimmung der Aminosäuren im Plasma oder im Serum. In vielen Fällen ist es nicht möglich, die Probe sofort zu analysieren oder optimal vorbereitet zu lagern.

Man kann davon àusgehen, daß einige Aminosäuren auch bei sofortigem Enteiweißen und Einfrieren verändert werden, während andere selbst dann noch sicher bestimmt werden können, wènn man das Vollblut über Stunden hinweg bei Raumtemperatur stehen läßt. Die vorliegende Arbeit sollte helfen, den Einfluß solcher Bedingungen quantitativ zu erfassen.

\section{Methoden und Mäterial}

\section{Probenvorbereitung}

Drei Frauen, 19, 22 und 40 Jahre alt und zwei Männern, 20 und 30 Jahre alt, wurde morgens nüchtern aus der leicht gestauten Vena cubitalis Blut abgenommen. Von je $5 \mathrm{ml}$ wurde nach spontaner Koagulation während 20 Minuten bei Raumtemperatur das Plasma durch 20 min Zentrifugieren bei $3500 \mathrm{U} / \mathrm{min}$ abgetrennt. Gelegentlich war es nötig, das an der Glaswandung haftende Fibrinogen mit einem Glasstab abzulösen und erneut 10 Minuten zu zentrifugieren. Dann wurden $2 \mathrm{ml}$ Plasma abpipettiert und mit der gleichen Menge Sulfosalicylsäure $(50 \mathrm{~g} / \mathrm{l})$ versetzt. Die Mischung wurde 2-3 Minuten bei Raumtemperatur leicht geschüttelt und anschließend 30 Minuten bei $3500 \mathrm{U} / \mathrm{min}$ zentrifugiert. $0,4 \mathrm{ml}$ des Uberstandes und $10 \mu \mathrm{l}$ der Lösung des 

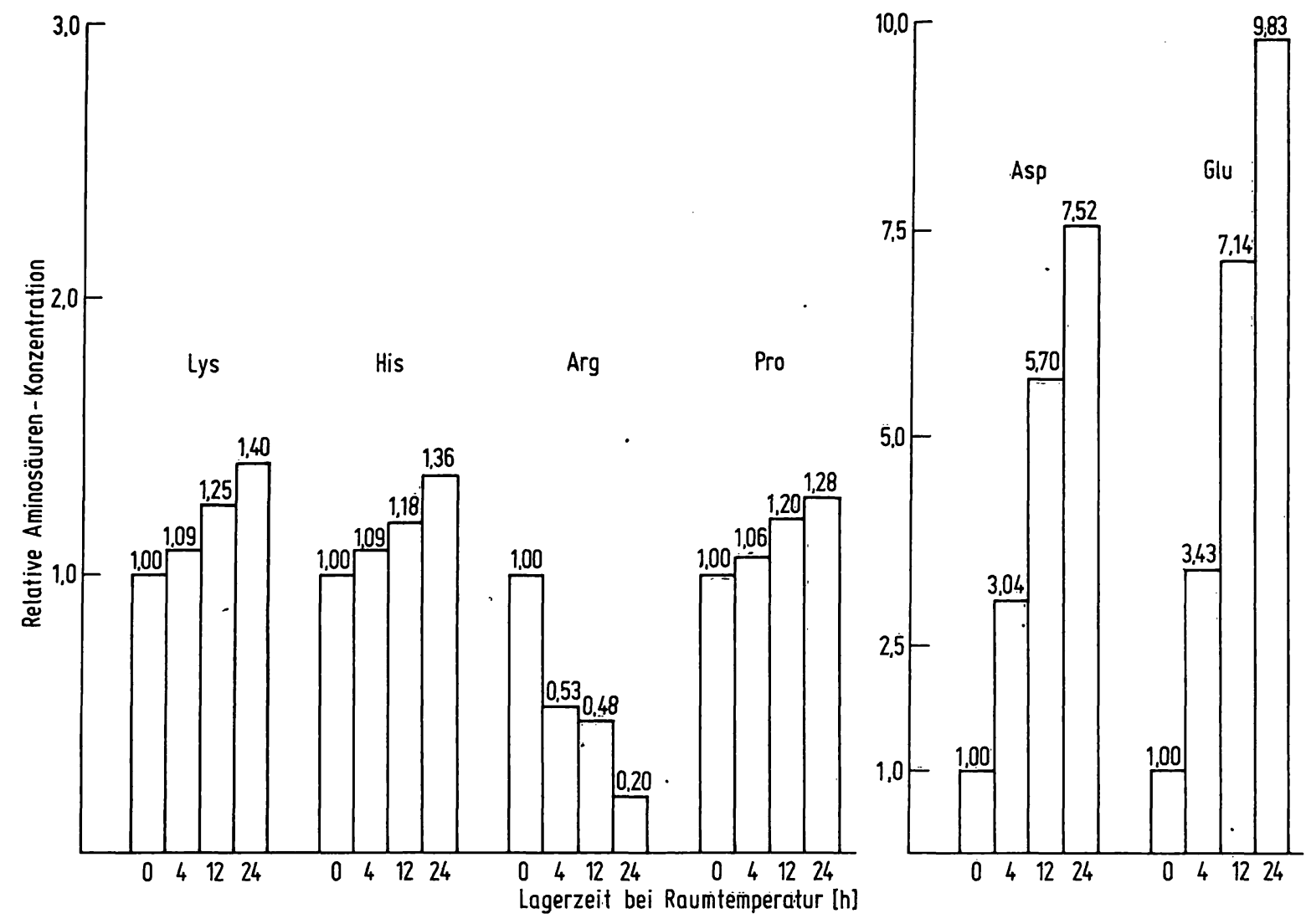

Abb. 1a.

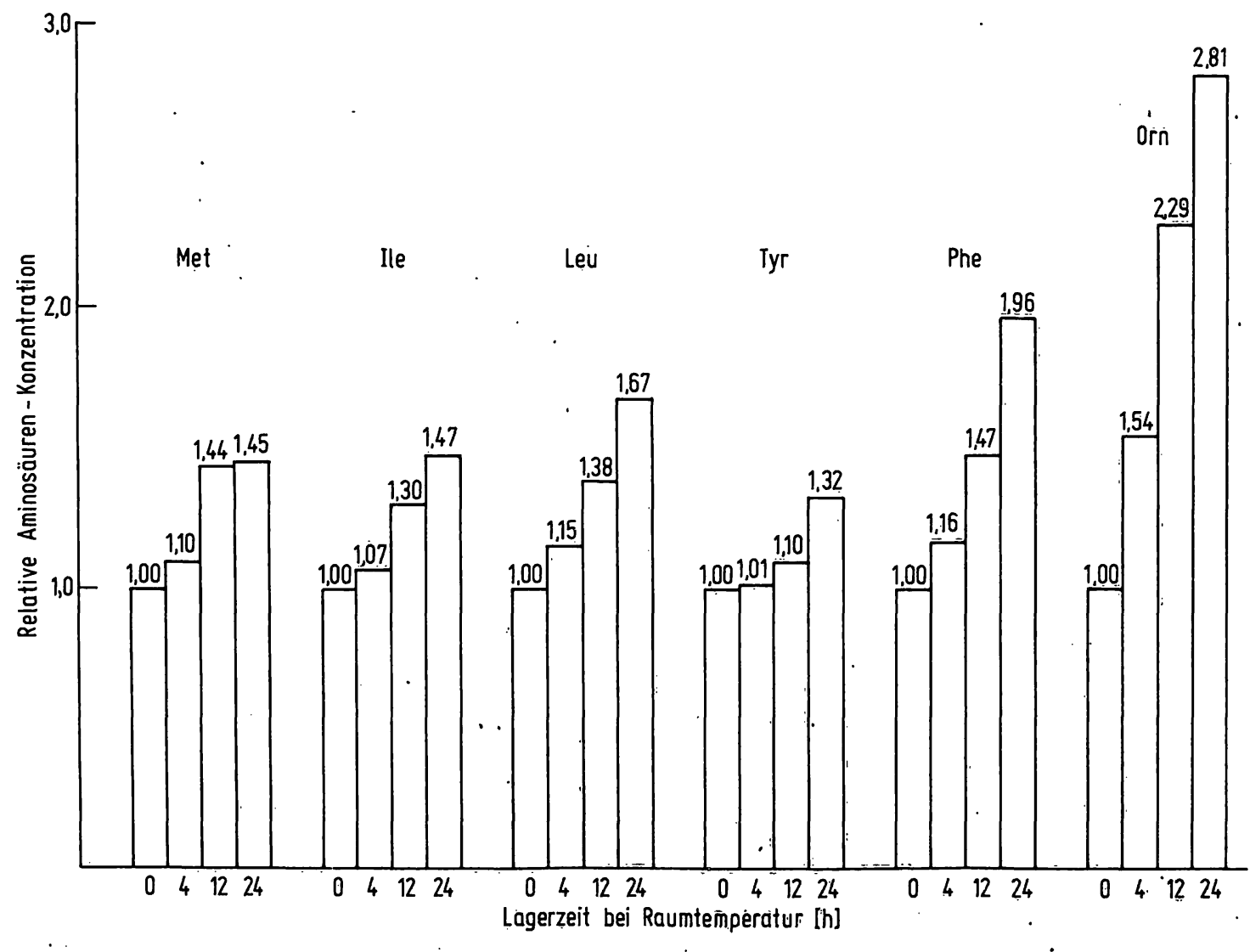

Abb. 1b. 


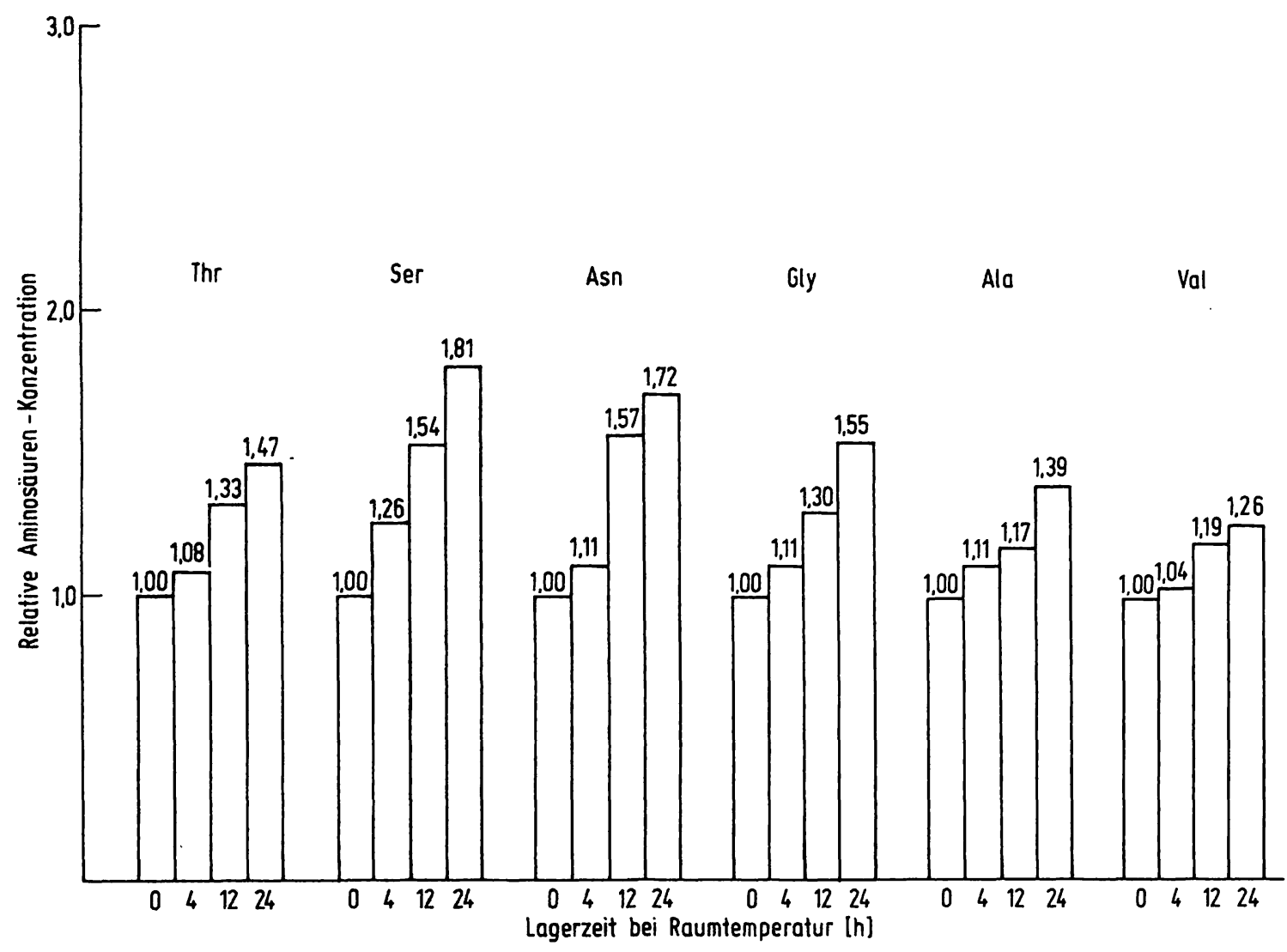

Abb. 1c.

Abb. 1. Einfluß der Lagerzeit von Vollblut bei Raumtemperatur auf die Konzentration von Aminosäuren im enteiweißten Serum. Die jeweiligen Werte $f$ wurden erhalten nach:

$\mathrm{f}=\frac{\overline{\mathbf{x}}_{\mathbf{0}}, \mathbf{4}, 12,24}{\bar{x}_{0}}$ mit: $\overline{\mathbf{x}}_{\mathbf{4}}, 12,24=$ Mittelwert der Konzentration der Aminosäuren im enteiweißten Serum nach Lagerung von Vollblut bei $20^{\circ} \mathrm{C}$ während 4,12 bzw. 24 Stunden.

$\overline{\mathbf{x}}_{\mathbf{0}}=$ Mittelwert der Aminosäurekonzentration im enteiweißten Serum, der durch sofortige Probenvorbereitung und Analyse erhalten wurde.

inneren Standards $(1,053 \mathrm{~g} / 1$ Norleucin in Wasser) wurden in den Analysator gegeben, der mit einer auf $+2^{\circ} \mathrm{C}$ gekühlten Probenaufgabenautomatik ausgerüstet war.

Jede Blutprobe exgab 13 Analy sen, die immer in der gleichen in Tabelle 1 angegebenen Reihenfolge analy siert wurden. Bei einer Analysendauer von 7,75 Stunden befánd sich die letzte Probe eines solchen Zyklus 69 Stunden in der Probenschleife. Ein separat durchgefụihrter Versuch zeigte, dạß auch die maximale Verweildauer bei dieser Temperatur keinen Einfluß auf die Konzentration hat.

\section{A naly senbed ingungen}

Dié Analysen wurden mit dern Automatischen AminosäureAnaly sator LC 6000 (Biotronik, München) angefertigt. Die quantitative Auswertung êrleichterte ein elektronischer Integrator (Autolab System I; Spectra Physics, Darmstadt). Getrennt wurde mit dem Kationenaustauscher Durrum DC6A, der in einer Glassäule mit dem Innendurchmesser $0,6 \mathrm{~cm}$ bis auf eine Höhe von $35 \mathrm{~cm}$ gepackt war.

Der Durchfluß der Elutionspiffer betrug konstant $38,5 \mathrm{ml} / \mathrm{h}$, der Durchfluß des Ninhydrinreagenz $19,25 \mathrm{ml} / \mathrm{h}$.

Żur Puffērherstellung wiurde eine $66,7 \mathrm{mmol} / 1$ Lithiumcitratlösung verwendet. Höhere Konzentrationen wurden durch Zusatz von $\mathrm{LiCl}$ erhalten. Der jeweilige pH-Wert wurde mit $\mathrm{LiOH}$ und HCl eingestellt.
Tab. 1. Form, Zeit und Temperatur, bei der eine Probe gelagert wurde, bevor sie den verbliebenen Probenvorbereitungsschritten unterworfen wurde. Die Probenvorbereitung bis zur jeweiligen Lagerform geschah sofort nach Blutentnahme.

\begin{tabular}{lcc}
\hline Lagerform & Lagerzeit $(\mathrm{h})$ & Lagertemperatur $\left.{ }^{\circ} \mathrm{C}\right)$ \\
\hline Serum, entei & & +20 \\
weißt & 0 & +20 \\
Vollblut & 4 & +20 \\
Serum & 4 & +20 \\
Serum, entei- & & +20 \\
weißt & 4 & +20 \\
Vollblut & 12 & -30 \\
Serum & 12 & +20 \\
Serum & 12 & -30 \\
Serum, entei- & & +20 \\
weißt & 12 & +20 \\
Serum, entei- & & -30 \\
weißt & 24 & \\
Vollblut & 24 & +20 \\
Serum & 24 & \\
Serum & 24 & \\
Serum, entei- & & \\
weißt & 24 & \\
\hline
\end{tabular}


Zur Elution wurden 4 Puffer verwendet:

Puffer A: $66,7 \mathrm{mmol} / \mathrm{l} ; \mathrm{pH}=2,45 ; \mathrm{mit} 2 \mathrm{ml} 350 \mathrm{~g} / \mathrm{kg}$ Brij 35; $2 \mathrm{ml}$ Thiodiglykol und $15 \mathrm{ml} n$-Propanol pro Liter

Puffer B: $66,7 \mathrm{mmol} / \mathrm{l} ; \mathrm{pH}=3,00 ; \mathrm{mit} 2 \mathrm{ml} 350 \mathrm{~g} / \mathrm{kg}$ Brij und $2 \mathrm{ml}$ Thiodiglykol pro Liter

Puffer C: $166,7 \mathrm{mmol} / 1 \mathrm{pH}=3,01 ; \mathrm{mit} 2 \mathrm{ml} 350 \mathrm{~g} / \mathrm{kg}$ Brij und $2 \mathrm{ml}$ Thiodiglykol pro Liter

Puffer D: $500 \mathrm{mmol} / \mathrm{l} \mathrm{pH}=3,48 ; \mathrm{mit} 2 \mathrm{ml} 350 \mathrm{~g} / \mathrm{kg}$ Brij 35 pro Liter

Mit folgendem Programm wurde eluiert:

a) Probenaufgabe; Elution während 90 min mit Puffer B bei $37^{\circ} \mathrm{C}$

b) Elution während $25 \mathrm{~min}$ mit Puffer $\mathrm{C}$ bei $37^{\circ} \mathrm{C}$

c) Elution während $55 \mathrm{~min}$ mit Puffer $\mathrm{C}$ bei $52^{\circ} \mathrm{C}$

d) Elution während $110 \mathrm{~min}$ mit Puffer D bei $52^{\circ} \mathrm{C}$

e) Elution während $65 \mathrm{~min}$ mit Puffer D bei $65^{\circ} \mathrm{C}$

f) Regeneration der Säule mit $0,3 \mathrm{~mol} / 1 \mathrm{LiOH}$ während $30 \mathrm{~min}$ bei $65^{\circ} \mathrm{C}$

g) Äquilibrieren der Säule mit Puffer A während 40 min bei $65^{\circ} \mathrm{C}$

h) Abkühlen der Säule von $65^{\circ} \mathrm{C}$ auf $37^{\circ} \mathrm{C}$ während $10 \mathrm{~min}$ ohne Pufferdurchfluß

i) Äquilibrieren der Säule mit Puffer A während $40 \mathrm{~min}$ bei $37^{\circ} \mathrm{C}$

Die Ninhydrin-Lösung wurde wie folgt hergestellt:

$544 \mathrm{~g} \mathrm{CH}_{3} \mathrm{COONa} \cdot 3 \mathrm{H}_{2} \mathrm{O}$ werden in ungefähr $500 \mathrm{ml} \mathrm{H}_{2} \mathrm{O} \mathrm{mit}$ $100 \mathrm{ml} \mathrm{CH}{ }_{3} \mathrm{COOH}$ gelöst und mit $\mathrm{H}_{2} \mathrm{O}$ auf ein $\mathrm{l}$ aufgefüllt, und mit 31 Ethylenglykolmonomethyläther in einer $\mathrm{N}_{2}$-Atmosphäre gemischt. Ebenfalls noch unter Luftabschluß wurden in dieser Mischung $80 \mathrm{~g} \mathrm{Ninhydrin} \mathrm{und} 2 \mathrm{~g} \mathrm{SnCl}_{2}$ gelöst. Die fertige

Lösung wurde unter einem $\mathrm{N}_{2}$-Polster aufbewahrt. Die Reaktion mit den Aminosäuren erfolgte in einem Wasserbad bei $100^{\circ} \mathrm{C}$.

\section{Ergebnisse}

\section{Qualitätskriterien}

Erwartungsgemäß zeigten Wiederholmessungen von Standardlösungen im Vergleich zu Wiederholmessungen von Serumproben eine etwas bessere Präzision (Tab. 2). Die Serumproben wurden geteilt und bei $-30^{\circ} \mathrm{C}$ bis zur eigentlichen Analyse eingefroren.

Zur Bestimmung der Richtigkeit wurden die folgenden Analysen durchgeführt:

a) 0,4 ml Serum + 0,1 ml Sulfosalicylsäure (25 g/l)

b) $0,1 \mathrm{ml}$ Standardlösung $+0,4 \mathrm{ml}$ Sulfosalicylsäure $(25 \mathrm{~g} / \mathrm{l})$

c) $0,4 \mathrm{ml}$ Serum $+0,1 \mathrm{ml}$ Standardlösung

Die Differenz von c) und a) wurde dann in Beziehung zu den bei b) gefundenen Flächenwerten gesetzt. Die Ergebnisse sind in Tabelle 3 wiedergegeben. Da die aus drei Werten ermittelte Präzision vergleichbar mit den bei Wiederholmessungen erhaltenen Werten war, wurde auf weitere Analysen verzichtet.

\section{Einfluß der Lagerform und der Lagerbedingungen auf die Konzentration}

Tabelle 4 gibt die Konzentrationen im Serum der 5 Personen an, die durch sofortige Probenvorbereitung und Analyse erhalten wurden. Die Mittelwerte wurden gleich 1 gesetzt und entsprechen dem jeweils èrsten Wert in den Abbildungen.
Tab. 2. Präzision von Wiederholungsmessungen in Standardlösungen und enteiweiß tem Serum (Cit = Citrullin; $\mathrm{Aad}=$ $\alpha$-Aminoadipinsäure; Cyt = Cystathionin.

\begin{tabular}{|c|c|c|c|c|}
\hline \multicolumn{2}{|c|}{ Standardlösung $(n=10)$} & \multirow{3}{*}{$\begin{array}{l}\text { Variations- } \\
\text { koeffizient } \\
\text { (\%) }\end{array}$} & \multicolumn{2}{|c|}{ Serum $(n=8)$} \\
\hline $\begin{array}{l}\text { injizierte } \\
\text { Menge }\end{array}$ & $\begin{array}{l}\text { wiederge- } \\
\text { fundenen }\end{array}$ & & Mittelwert & $\begin{array}{l}\text { Variations- } \\
\text { koeffizient }\end{array}$ \\
\hline (nmol) & (nmol) & & $($ imol/l) & (\%) \\
\hline 47,17 Asp & 47,09 & 1,09 & 17,9 & 3,7 \\
\hline $47,17 \mathrm{Thr}$ & 47,21 & 1,48 & 102,5 & 3,3 \\
\hline 47,17 Ser & 46,88 & 1,16 & 139,2 & 3,3 \\
\hline 23,58 Asn & 23,54 & 2,71 & 87,6 & 6,7 \\
\hline $47,17 \mathrm{Glu}$ & 46,53 & 0,99 & 45,7 & 9,6 \\
\hline 11,79 Aad & 10,98 & 2,89 & 6,9 & 6,2 \\
\hline 47,17 Pro & 47,56 & 0,80 & 271,2 & 1,5 \\
\hline 47,17 Gly & 47,60 & 1,08 & 303,2 & 3,1 \\
\hline $47,17 \mathrm{Ala}$ & 47,47 & 1,50 & 454,5 & 2,1 \\
\hline $11,79 \mathrm{Cit}$ & 12,21 & 2,26 & $31,5$. & 3,4 \\
\hline $47,17 \mathrm{Abu}$ & 47,47 & 1,50 & 49,1 & 3,8 \\
\hline $47,17 \mathrm{Val}$ & 47,79 & 1,11 & 280,6 & 1,8 \\
\hline 23,58 Cys & 23,65 & 4,32 & 61,6 & 3,3 \\
\hline 47,17 Met & 47,41 & 0,78 & 56,7 & 3,7 \\
\hline 23,58 Cyt & 23,51 & 2,16 & & \\
\hline 47,17 He & 47,18 & 1,17 & 89,6 & 4,1 \\
\hline $47,17 \mathrm{Leu}$ & 47,11 & 0,62 . & 129,7 & 2,4 \\
\hline 47,17 Tyг & 47,87 & 1,10 & 91,1 & 2,2 \\
\hline 47,17 Phe & 47,44 & 0,88 & 77,1 & 3,3 \\
\hline 47,17 Orn & 47,05 & 0,88 & 99,9 & 2,9 \\
\hline 47,17 Lys & 47,02 & 0,87 & 260,4 & 2,6 \\
\hline $\begin{array}{c}47,171 \mathrm{Me} \\
\mathrm{His}\end{array}$ & 48,50 & 2,22 & & \\
\hline 47,17 His & 48,47 & 1,91 & 100,7 & 1,6 \\
\hline $\begin{array}{c}47,173 \mathrm{Me}- \\
\mathrm{His}\end{array}$ & 47,71 & 0,57 & 16,3 & 4,9 \\
\hline 47,17 Trp & 46,67 & 1,58 & 84,5 & 4,7 \\
\hline 47,17 Arg & 44,95 & 3,81 & 128,6 & 9,3 \\
\hline
\end{tabular}

Tab. 3. Richtigkeit der Serumanalysen $(n=3)$ Cit = Citrullin).

\begin{tabular}{lrl}
\hline Aminosäure & Wiederfindung & $\begin{array}{l}\text { Variationskoeffizient } \\
(\%)\end{array}$ \\
\hline Asp & 95,2 & 4,0 \\
Thr & 97,6 & 2,9 \\
Ser & 97,5 & 3,2 \\
Asn & 92,4 & 2,3 \\
Glu & 93,8 & 6,1 \\
Pro & 96,5 & 6,6 \\
Gly & 95,2 & 3,7 \\
Ala & 97,4 & 7,7 \\
Cit & 95,8 & 6,0 \\
Abu & 97,8 & 2,8 \\
Val & 92,6 & 0,8 \\
Cys & 95,2 & 3,8 \\
Met & 101,4 & 6,7 \\
Ile & 97,5 & 6,1 \\
Leu & 99,7 & 7,3 \\
Tyr & 98,1 & 5,2 \\
Phe & 98,7 & 2,1 \\
Orn & 97,3 & 6,3 \\
Lys & 98,9 & 5,9 \\
His & 100,0 & 2,3 \\
Trp & 100,1 & 3,5 \\
Arg & 97,4 & 8,2 \\
\hline
\end{tabular}

Nur die Aminosäuren Citrullin, $\alpha$-Aminobuttersäure, Cystein und Tryptophan erfahren keine Konzentrationsänderung, wenn Vollblut $24 \mathrm{~h}$ bei Raumtemperatur gelagert wird. Die Konzentration der übrigen Aminosäuren ändert sich dagegen um die in Ảbbildung 1 a-c angegebe- 
Tab. 4. Konzentrationen von Aminosäuren im Serum in $\mu \mathrm{mol} / 1$ der 5 Probanden, die durch sofortige Probenvorbereitung und Analyse erhalten wurden. Cit $=$ Citrullin

\begin{tabular}{lrrrrrr}
\hline Amino- & \multicolumn{7}{c}{ Proband } \\
säure & $9,40 \mathrm{a}$ & $9,22 \mathrm{a}$ & $0,30 \mathrm{a}$ & $0,20 \mathrm{a}$ & $9,19 \mathrm{a}$ & $\overline{\mathbf{x}}$ \\
\hline Asp & 13,8 & 7,7 & 6,7 & 6,5 & 6,0 & 8,1 \\
Thr & 133,3 & 77,5 & 97,3 & 155,3 & 172,3 & 127,1 \\
Ser & 121,4 & 113,1 & 87,6 & 122,0 & 157,1 & 122,2 \\
Asn & 61,4 & 58,3 & 55,2 & 44,1 & 70,0 & 57,8 \\
Glu & 45,6 & 30,3 & 38,0 & 26,1 & 40,9 & 36,2 \\
Pro & 336,5 & 164,6 & 202,4 & 188,4 & 184,8 & 215,3 \\
Gly & 222,7 & 255,4 & 194,4 & 241,9 & 270,6 & 245,0 \\
Ala & 361,9 & 397,1 & 269,3 & 252,8 & 334,1 & 323,0 \\
Cit & 18,6 & 25,4 & 27,8 & 47,5 & 18,1 & 27,5 \\
Abu & 18,7 & 19,9 & 13,3 & 31,0 & 24,3 & 21,5 \\
Val & 260,5 & 209,1 & 226,8 & 271,3 & 234,3 & 240,4 \\
Cys & 59,9 & 49,5 & 60,4 & 49,8 & 54,1 & 54,7 \\
Met & 24,1 & 22,8 & 24,6 & 34,1 & 36,5 & 28,4 \\
Ile & 52,3 & 51,8 & 63,3 & 89,1 & 69,5 & 65,2 \\
Leu & 101,9 & 96,2 & 113,7 & 143,5 & 106,0 & 112,3 \\
Tyr & 66,6 & 72,5 & 58,4 & 59,5 & 92,0 & 69,8 \\
Phe & 52,6 & 70,8 & 59,0 & 67,5 & 76,9 & 65,4 \\
Om & $*$ & 93,1 & 55,3 & 78,8 & 81,3 & 77,1 \\
Lys & 175,0 & 168,4 & 182,1 & 190,5 & 220,1 & 187,2 \\
His & 96,7 & 98,3 & 79,9 & 87,5 & 97,1 & 91,9 \\
3Me-His & 9,7 & 5,0 & 5,3 & - & - & 4,0 \\
Try & 61,9 & 96,2 & 54,7 & 78,1 & 77,1 & 68,2 \\
Arg & 133,2 & 139,1 & 74,1 & 103,7 & 99,5 & 109,9 \\
\hline
\end{tabular}

* Störung im Chromatogramm

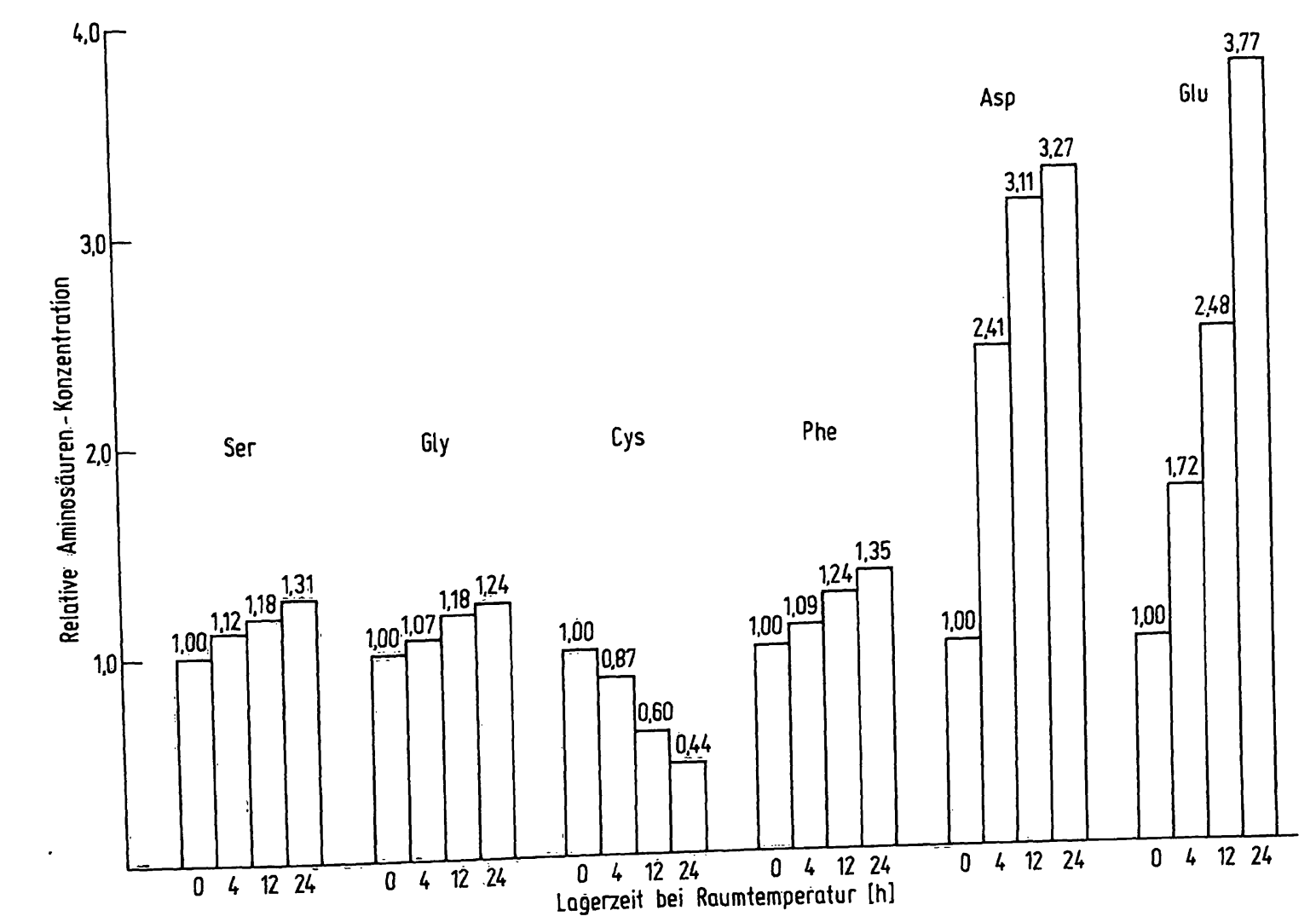

Tab. 5. Faktoren, um die sich die Konzentration von Asparaginund Glutaminsäure im Serum in Abhängigkeit von Lagerzeit und -temperatur ändert.

\begin{tabular}{llllllll}
\hline \multicolumn{7}{c}{ Raumtemperatur } & \multicolumn{3}{l}{$-30^{\circ} \mathrm{C}$} \\
& $4 \mathrm{~h}$ & $12 \mathrm{~h}$ & $24 \mathrm{~h}$ & $1 \mathrm{~d}$ & $10 \mathrm{~d}$ & $20 \mathrm{~d}$ & 30d \\
\hline Asp & 0,94 & 0,96 & 0,99 & 0,96 & 1,02 & 1,23 & 1,37 \\
Glu & 1,07 & 1,33 & 1,54 & 1,17 & 2,26 & 2,40 & 2,73 \\
\hline
\end{tabular}

nen Faktoren. Hierbei nehmen Asparaginsäure, Glutaminsäure, Ornithin und, im umgekehrten Sinne, Arginin eine herausragende Stellung ein.

Wird Plasma dagegen bis zu $24 \mathrm{~h}$ bei Raumtemperatur aufbewahrt, so reduziert sich die Anzahl der Aminosäuren, die eine Konzentrationsänderung erfahren von 18 auf 6 (Abb. 2). Gleichzeitig verringern sich die entsprechenden Faktoren. Aber auch jetzt besitzen Asparagin- und Glutaminsäure noch die größten $\mathrm{Faktoren}$.

Einfrieren des Plasmas bei $-30{ }^{\circ} \mathrm{C}$ bewirkt, daß die $\mathrm{Zu}$ sammensetzung bis $24 \mathrm{~h}$ konstant bleibt.

Serum dagegen läßt sich sowohl bei Raumtemperatur bis zu $24 \mathrm{~h}$ als auch bei $-30^{\circ} \mathrm{C}$ bis zu einem Monat messen,

Abb. 2. Einfluß der Lagerzeit von Serum bei Raumtemperatur auf die Kọnzeṇtration von Aminosäuren im enteiweißten Serum. Die jeweiligen Werte $f$ wurden erhalten nach $\mathrm{f}=\frac{\overline{\overline{\mathrm{x}}}_{\mathbf{0}}, 4,12,24}{\overline{\mathrm{x}}_{0}}$ mit: $\overline{\mathrm{x}}_{4,12,24}=$ Mittelwert der Aminosäurekonzentration im enteiweißten Serum nach Lagerung von Serum bei $20^{\circ} \dot{C}$ während 4,12 bzw. 24 Stunden.

$\overline{\mathbf{x}}_{0}=$ Mittelwert dèr Aminosäurekonzentratiọn im enteiweißten Serum, der durch sofortige Probenvorbereitung und Analyse erhalten wurde. 
ohne daß Korrekturfaktoren eingefuihrt werden müssen Eine Ausnahme bilden auch hier wieder Asparagin- und Glutaminsäure, wie aus Tabelle $5 \mathrm{zu}$ ersehen ist.

\section{Diskussion}

Nur bei einem Teil der hier beschriebenen Aminosäuren hat man eine Vorstellung vom Mechanismus, der den Konzentrationsänderungen zu Grunde liegt.

Der starke Anstieg der Aspargin- und Glutaminsäure mag damit zusammenhängen, daß in den Granulocyten diese Substanzen in hohen Konzentrationen erhalten sind. Sicher spielt auch die Umwandlung von Glutamin in Glutaminsäure eine wesentliche Rolle $(1,2)$.

\section{Literatur}

1. Dickinson, J. C., Rosenblum, H. \& Hamilton, P. B. (1965) Pediatrics 36, 2-13

2. Huopert, Y., Tarallo, P. \& G. Siest (1975) J. Chromatogr. 115, $33-40$

3. Billmeir, G. J., Molinary, S. V., Wilroy, R. S., Duenas, D. A. \& Brannon, M. E. (1974) J. Pediat. 84, 85-89
Uber Ihre Funktionen im Harnstoffzyklus hängen der Anstieg des Ornithin und der Abfall des Arginin im Vollblut zusammen: in den Erythrocyten wurde die Arginase und die Argininobernsteinsäurelyase nachgewiesen $(3,4)$; in den Lymphocyten die Argininobernsteinsäuresynthetase (5) und dort in den Mitochondrien die Ornithin-Carbamoyltransferase.

Die Erythrocytenenzyme scheinen leichter zugänglich zu sein als die der Lymphocyten, so daß Arginin weiter abgebaut wird, das Ornithin aber nicht.

Dem Cystein und dem Tryptophan werden eine ausgeprägte Affinität zu Plasmạpproteinen zugeschrieben (6). Solch ein Effekt ist wahrscheinlich dafuir verantwortlich, daß Cystein im unbehandelten Serum stark abnimmt, nicht aber im enteiweißten.

4. Snyderman, S. E., Sansaricg, G., Chen, W. J., Morton, P. M. \& Phansalhar (1977) J. Pediat. 90, 563-568

5. Spector, E. B., Lockridge, I. \& Bloom, A. D. (1975) Biochem. Gen. 13, 471-485

6. Stein, W. H. \& Moore, S. (1954) J. Biol. Chem. 211, 915-920

Dr. K. Olek

Inst. f. Humangenetik der Universität Wilhelmstr. 31 D-5300 Bonn 


\section{Moderne Dünnschicht-Chromatographie} bietet entscheidende vorteile. Um sie zu nutzen, benötigen sie ein KOMPLETTES SYSTEM optimal aufeinander abgestimmter Geräte.

\section{Beispiel für ein komplettes System für die konventionelle Dünnschicht-Chromatographie}

\section{Probendosieren}
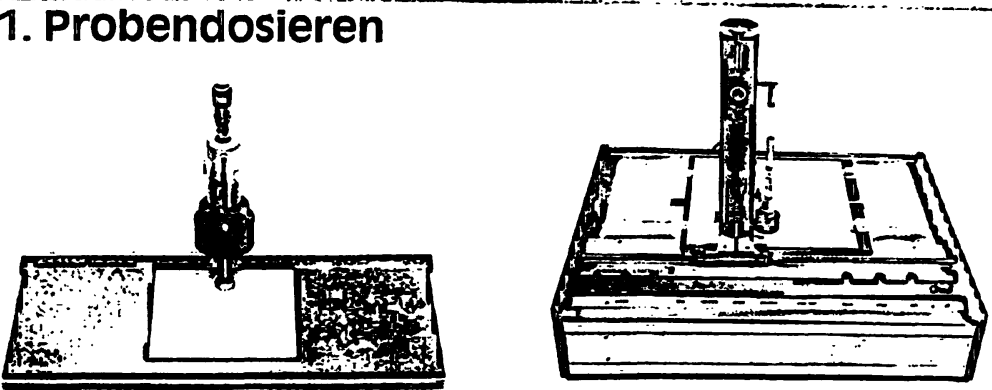

CAMAG Micro-Applicator Auftragen varlabler Probenvolumina $0.5-2.3 \mu l$ (punktförmig) mit einer Reproduzierbarkeit von $1 \%$

CAMAL LINOMAT II"

Auftragen grösserer Probenvolumina (ca. 5-500 $\mu \mathrm{l}$, strichförmig), Reproduzierbarkeit ca. $1 \%$.
Làssen Siè sicch auch über komplette CAMAG Systeme für die Hochleistungs:

Dünnschicht-chromatogọaphie informiereñ.

Die imit * gèkennzeichneten Gèäte sind übrigens mit diesen kompatibel.
2. Entwickeln

CAMAL

Doppeltrogkammer

flexibel,

sparsam im Fliessmittelverbrauch, reproduzierbare Bedingungen.

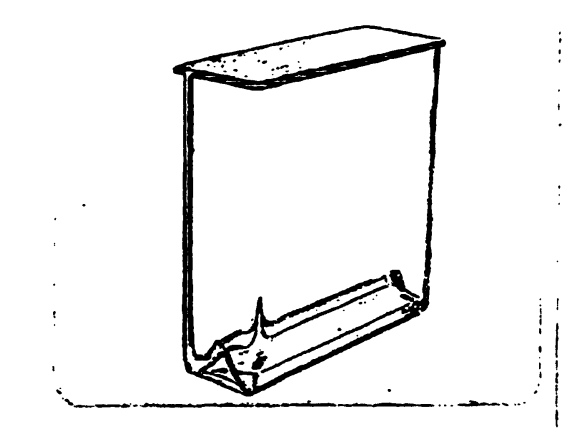

Ob Sie ein neues DC-Labor einrichten wollen oder eîn bestehendes mit modernen, leistung gsfähigen Geräten ausbauen wollen, fragen Sie den CAMAG Spezialisten.

\section{Quantitative Auswertung} CAMAG DC/HPDC Scanner* Wahlweise als preisgünstiges filtergerät oder in Monochromator-Ausführung erhältlich.

Auswertemodi: Absorption, Fluoreszenz, Fluoreszenzlöschung.

Sie können dem Gerät dle automatische Auswertung der Messbahnen eines ganzen chromatogramms überlassen.

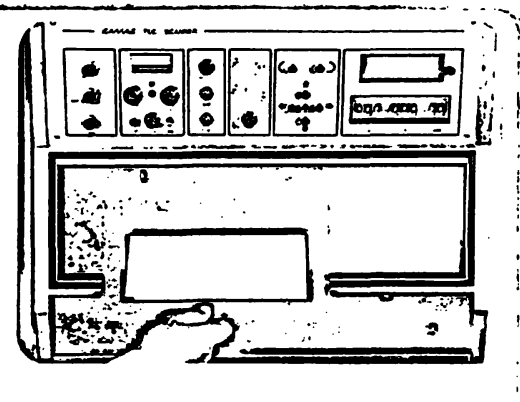
. 
An der

Veterinärmedizinischen Universität Wien gelangt am Institut für Biochemie die Planstelle eines Ordentlichen Universitätsprofessors für Biochemie (Nachfolge von O. Univ. Prof. Dr. Wilhelm Stöckl) zur Wiederbesetzung

Bewerber haben ihre bisherige Tätigkeit schriftlich darzustellen und eine Liste der wissenschaftlichen Veröffentlichungen sowie der sonstigen wissenschaftlichen Arbeiten ihrem Bewerbungsschreiben anzuschließen.

Ende der Bewerbungsfrist: 30. November 1979

Anschrift:

Veterinärmedizinische Universität Wien, Universitätsdirektion,

zu Händen von Herrn O. Univ. Prof. Dr. Alfred Kment,

Vorsitzender der Berufungskommission, 1030 Wien, Linke Bahngasse 11.

Die Bewerbungen sind mit ÖS 70,-, jede Beilage mit ÖS 20,-

Bundesstempelmarke zu vergebühren.

\section{Facharzt für Laboratoriums- medizin}

als Partner für die

Gründung eines medizinischen Labors gesucht.

Einrichtung und endgültiger Standort können gemeinsam bestimmt werden.

Finanzielle Beteiligung

ist nicht erforderlich.

Anfragen erbeten unter

Chiffre KC 979

an die

Merkur Werbung GmbH,

Postfach 1245, 5210 Troisdorf 1 \begin{tabular}{ll}
\hline $\begin{array}{l}\text { W } \\
\text { of } \\
\text { G }\end{array}$ & $\begin{array}{l}\text { Walter de Gruyter } \\
\text { Berlin.New York }\end{array}$ \\
\hline
\end{tabular}

\section{Eckhart Buddecke}

\section{Pathobiochemie}

Ein Lehrbuch für Studierende und Ärżte

$17,0 \mathrm{~cm} \times 24,0 \mathrm{~cm} . X X X V I, 446$ Seiten. Mit 247 Abbildungen und zahlreichen Tabellen. 1978. Plastik flexibel DM 34,ISBN 3110075261

Das Lehrbuch Pathobiochemie beschreibt die biochemischen Grundlagen genetischer und erworbener Störungen des Stoffwechsels, Abweichungen in der chemischen Struktur der Bausteine des menschlichen Körpers, fehlerhafte biochemische Prozesse, soweit sie sich als Symptome mit Krankheitswert manifestieren.
Als einführendes Lehrbuch umfaßt die Pathobiochemie die Hauptabschnitte: Stoffwechsel, Stoffwechiselregulation, Zellén, Gewebe und Organe und Dynamische Systeme.

Die Pathobiochemie liefert der Medizin neue theoretische Grundlagen, zeigt, in welchen Bereichen ein erfolgreicher Vorsto $B$ bis. zu einer "molekularen Krankheitslehre" möglich ist, und vermittelt als fachgebietsübergreifende Wissenschaft auch Beziehungen żu zahlreichen Nachbargebieten wie z. B., zu Pathologie, Immunologie, Pharmakologie, Klinischer Chemie und Innerer Medizin.

Bei der Auswahl des Stoffes wurde die revidierte und neugegliederte 2. Auflage (1978) des Gegenstandskataloges "Pathophysiologie und Pathobiochemile" eingehend berücksichtigt.

Ein entsprechendes Korrelationnsregister zum GK ist dem Buch beigefügt.

Preisaanderungen vorbehalten 